\title{
A Study on the Correlation of Physiological and Psychological Health Hazards in Human Habitats with Seismicity, Mountain Air Turbulence and Environmental Infrasound
}

\author{
R. Gopalaswami* \\ Bharat Dynamics Ltd., Hyderabad, India \\ Email: gopalaswami@gmail.com
}

How to cite this paper: Gopalaswami, R. (2018) A Study on the Correlation of Physiological and Psychological Health Hazards in Human Habitats with Seismicity, Mountain Air Turbulence and Environmental Infrasound. Open Journal of Earthquake Research, 7, 69-87.

https://doi.org/10.4236/ojer.2018.72005

Received: February 18, 2018

Accepted: March 24, 2018

Published: March 27, 2018

Copyright $\odot 2018$ by author and Scientific Research Publishing Inc. This work is licensed under the Creative Commons Attribution International License (CC BY 4.0).

http://creativecommons.org/licenses/by/4.0/

\begin{abstract}
A statistical correlation study on the basis of published data has been performed in order to find whether an abnormal degree of human physiological ailments and a psychology of sustained violent reactions in highly populated habitats are correlated with environmental infrasound emissions related to seismic activity and sustained by mountain air turbulence. The study focus is on Latitude $34^{\circ}$ North coinciding with boundaries of colliding Tectonic Plates in three continents. Earthquakes, rock fractures and landslides in these regions are creating geoacoustic activity in the form of hotspots of infrasound emissions. Sources of infrasound have been located by global infrasound monitoring stations. One single earthquake can cause multiple infrasound sources in a region. Low frequency "infrasound" creates an environment of unseen and inaudible energies that are hazardous to the local population. In one region on $34^{\circ} \mathrm{N}$ latitude the percentage of population with hearing disabilities increases or decreases almost directly proportional to frequency of earthquakes. In this region, the casualties due to social disorder and violence increased as the frequency of earthquake events increased and decreased as this frequency decreased. Comprehensive public health studies bring out that a sizable percentage of the regional population remain in a constant state of irritation, annoyance and anger; and suffer many other psychosomatic ailments corresponding to exposure to infrasound in $5-16 \mathrm{~Hz}$ frequencies and $120-140 \mathrm{~dB}$ amplitude. A new natural hazard inimical to life on planet earth has thus been identified. The time has arrived for public health authorities to locally pinpoint infrasound hotspots by scientific measurements. Thereafter new technologies can be developed to actively, and passively, mitigate/cancel these
\end{abstract}

*(Retired) formerly CMD, Bharat Dynamics Ltd., Hyderabad, India. 
hazardous environmental emissions of infrasound and a Public Health Security Systems put in place as sustainable solutions for a healthy, livable habitat.

\section{Keywords}

Environmental Infrasound, $34^{\circ}$ North Parallel, Geoacoustic Hot Spots, Hearing Disabilities, Noise Cancellation

\section{Introduction}

As the years go by, more and more catastrophic natural events like earthquakes, tsunamis, volcanic eruptions etc. are bringing out that environmental disasters have tended to become more intense. This study draws attention to a new form of natural hazard-environmental infrasound-that affects exploding populations living in regions of the world which are bordering the boundaries of colliding tectonic plates. Mighty mountain ranges have been created at the boundaries of colliding tectonic plates. These regions are the home of intense seismic activity like earthquakes and rock fractures over large zones. The release of vast amounts of trapped subterranean energies in the form of inaudible "infrasound" from these seismic events and also from mountain clear air turbulence is extremely hazardous to life, tending to make these regions inhospitable habitats. All available scientific evidence from a variety of fields of science when correlated indicate mankind can no longer ignore this natural hazard, progressively becoming lethal to civilized life on planet earth.

\section{Methodology}

The whole process of analysis is illustrated in Figure 1. The primary data sources to establish the central idea that human habitats in certain specific high seismic and mountainous regions have become almost uninhabitable are as follows:

1) Data published by geologists and geophysicists show that colliding tectonic plates cause earthquakes and rock fractures at their boundaries.

2) Their recent published studies using global infrasound monitoring stations provide data to show that earthquakes and rock fractures release vast amounts of trapped subterranean energy that when detected are called infrasound "hotspots". The data shows that one earthquake can create multiple infrasound hotspots.

3) Hazardous environmental infrasound is also shown by actual measurements by scientists in the USA to emerge with clear air turbulence in mountainous regions.

4) Published Infrasound Toxicology studies show that infrasound in specific frequencies and amplitudes causes grave physiological and psychological health hazards in $10 \%-22 \%$ of populations. It is assumed in this Study that those individuals so "infected" by infrasound can (due to socio-economic and geopolitical 


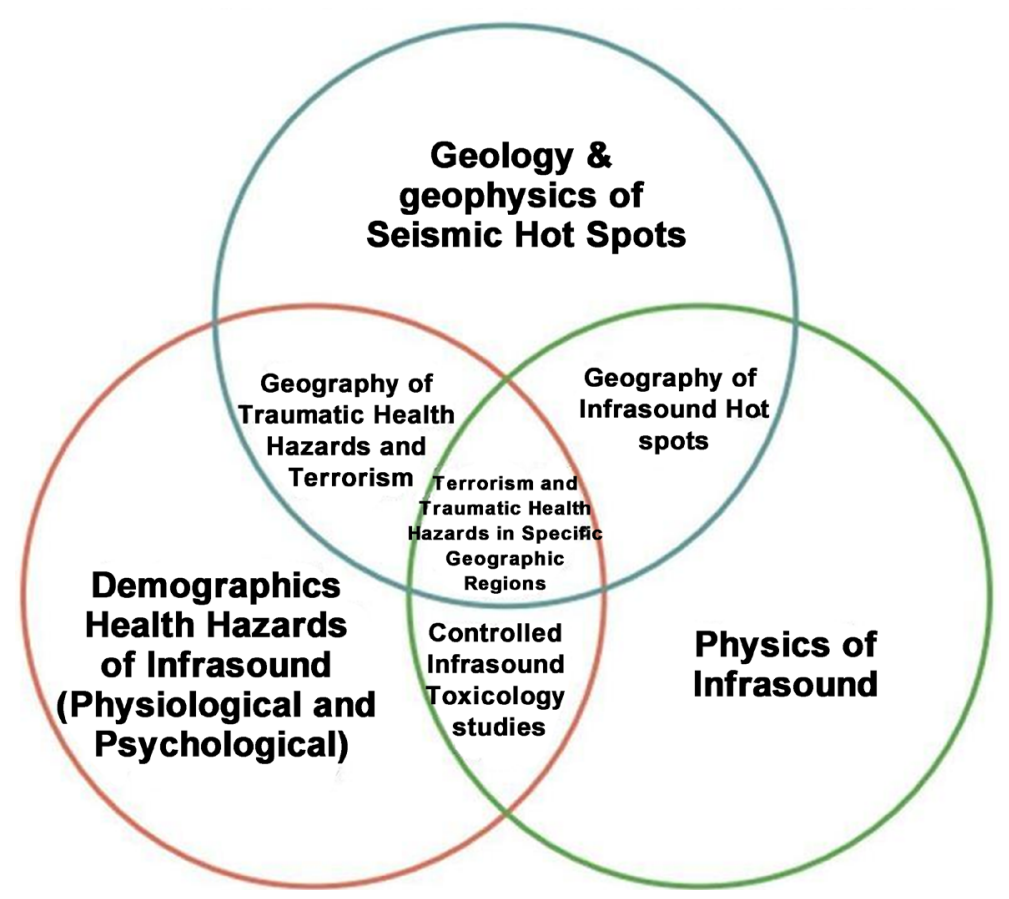

Figure 1. Methodology for bringing out the convergence of seismicity, infrasound and health hazards.

processes) progressively nucleate social disorder and violence; ultimately terrorism may emanate in and from these regions.

This process of analysis also reveals that geographical regions around $34^{\circ}$ North latitude are not just the seismic killing fields of mankind, but as local populations explode, are becoming regions of growing mental and physiological illness, brain damage and grave psychological ailments. Over the years they have increased and consolidated to result in social disorder and violence; and lead on in some regions to terrorism. This process is continuing, and is being interpreted as solely and exclusively due to genetic, historical, socio-economic and geo-political causes, and is hazardous to civilizations worldwide. This Study suggests a geoacoustic causal factor may be at the hard core of the problem of social disorder, violence and terrorism.

\section{Tectonic Plate Boundaries on $34^{\circ} \mathrm{N}$ Latitude-Environmental Killing Fields of Planet Earth}

The First Correlation: In the last few decades, the frequency of earthquakes, floods, heat/cold waves has gone up considerably. This study focuses on geographical regions that exist close to $34^{\circ}$ North latitude that lie on or very close to the boundaries of clashing tectonic plates. Large populations and high population density in regions that get hit by earthquakes, floods, landslides, drought, wildfires etc are resulting in more extensive loss of lives.

Over the centuries, these regions have witnessed environmental catastrophes wherein millions of human beings have lost their lives, property and livelihood destroyed by earthquakes, rock fracture and landslides. In the $20^{\text {th }}$ century alone, 
nearly two million people have died due to earthquakes in this region as shown in Figure 2 [1]. Predicting these natural disasters is not easy. There are also many geographical regions not on the $34^{\text {th }}$. Parallel that exhibit intense seismicity that is beyond the scope of this Study. There are also a large number of underground locations in all continents located within the tectonic plates were seismic "hotspots" exist [2]. The $34^{\text {th }}$ Parallel has been chosen because of the strange geological chance that the boundaries of colliding plates in these regions have for centuries past been centres of great earthquakes and social violence. In the last century this violence has spilled as a scourge far beyond the geographical region and is now termed as "terrorism".

\section{High Seismicity around Boundaries of Tectonic Plates at $34^{\circ}$ North Latitude}

The Second Correlation: Seismicity is defined by geophysicists as a measure which encompasses earthquake occurrences, mechanisms, and magnitude at a given geographical location. As such it is a term which summarizes a region's seismic activity like earthquakes, rock fractures, volcanoes etc. [3]. Figure 3 illustrates the global seismic centres on planet earth. It can be seen that the most seismic regions lie in the Asian continent along $34^{\circ} \mathrm{N}$ latitude; and along the Eastern and Western seaboards of Asia and North America. These regions are the focus of this Study. Such seismic activity is caused by plate tectonics. According to Encyclopedia Britannica, "plate tectonics" is a "geophysical theory that Earth's outer shell is divided into several plates that glide over the mantle, the rocky inner layer above the core. The plates act like a hard and rigid shell compared to Earth's mantle. This strong outer layer is called the lithosphere, which is $100 \mathrm{~km}$ (60 miles) thick. About 50,000 earthquakes large enough to be noticed without the aid of instruments occur annually over the entire Earth. Of

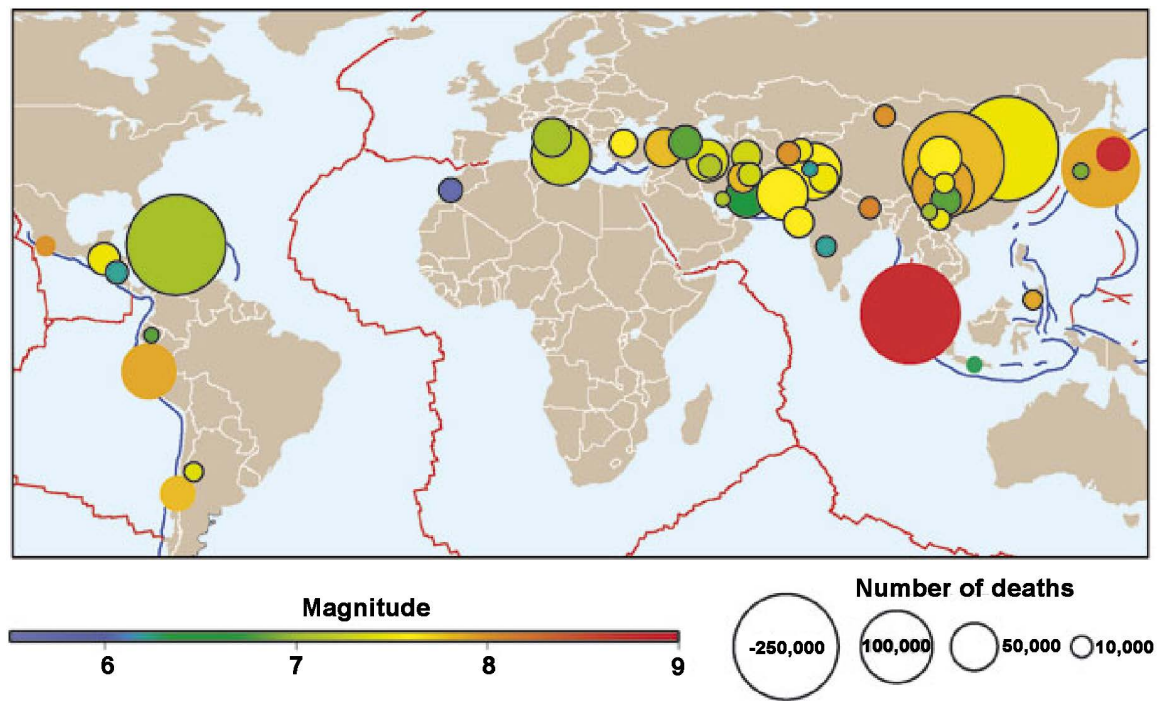

Figure 2. Geography of seismic hazards (with permission). http://bloggie-360.blogspot.in/2014/03/global-seismic-hazard-map-from-w3.html\#!/2014/ 03/global-seismic-hazard-map-from-w3.html. 


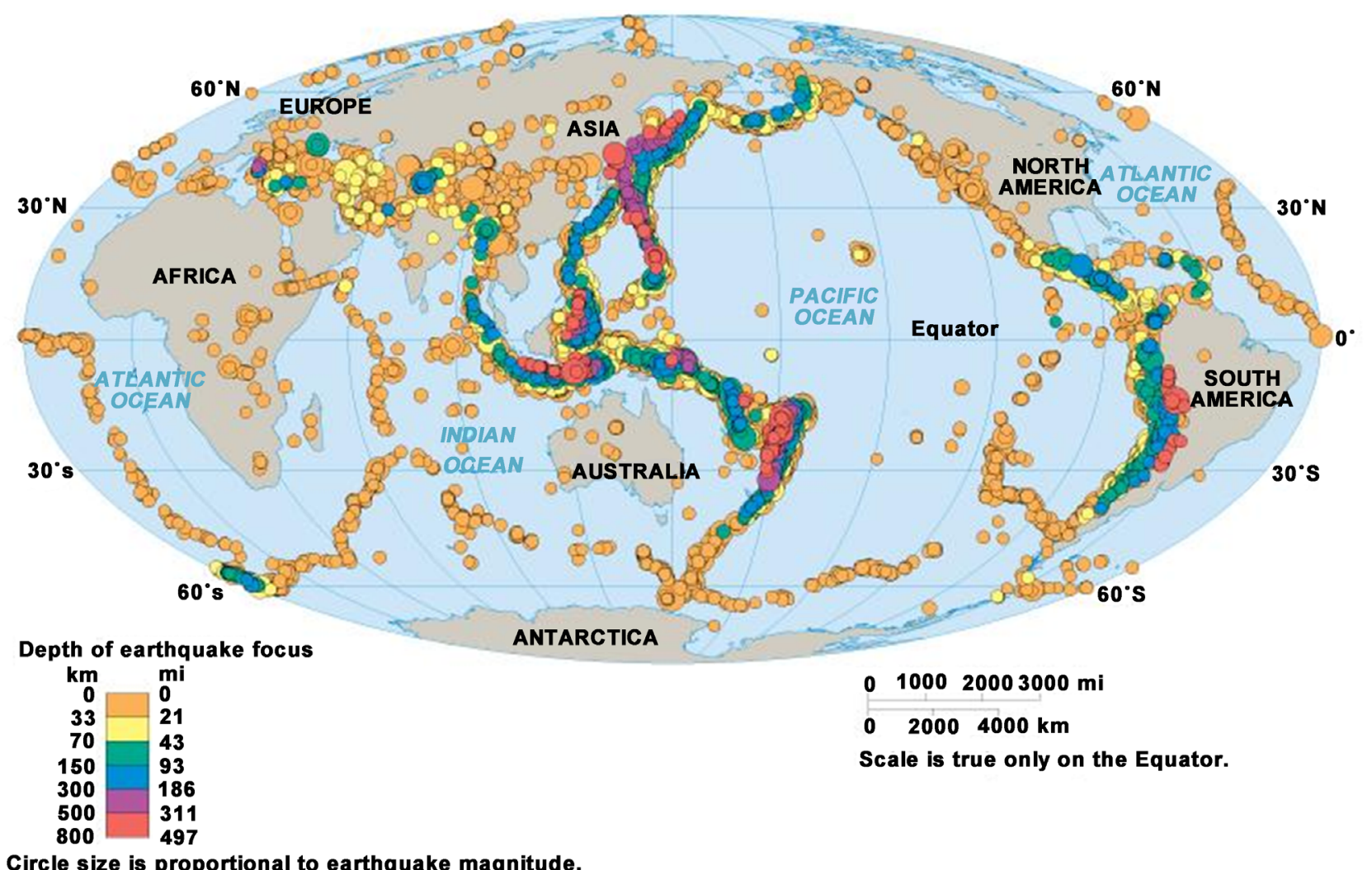

Figure 3. Global seismic centres in 1975-99: earthquakes of magnitude 5.5 and greater. ((With permission) by courtesy encyclopedia britannica inc copyright 2012 used with permission) http://www.britannica.com/science/earthquake-geology.

these, approximately 100 are of sufficient size to produce substantial damage if their centres are near areas of habitation. Very great earthquakes occur on average about once per year. Over the centuries they have been responsible for millions of deaths and an incalculable amount of damage to property" [4].

By a strange twist of fate, $34^{\circ}$ North latitude almost coincides with the boundary of colliding Indian/Arabian plates with the Eurasian plate. The $34^{\text {th }}$ degree north latitude spans across the most highly populated developing countries in the entire Asian continent a massive $120^{\circ}$ longitude or $1 / 3^{\text {rd }}$ of the circumference of the globe at that latitude i.e. over $10,000 \mathrm{Kms}$ of land mass. The $34^{\text {th }}$ Parallel runs through three continents, Asia, North America and North Africa. The colliding tectonic plates have created major mountain regions: the Rocky Mountains in USA bordering the Atlantic Ocean to the Himalayan mountain ranges in Asia, spreading across South and down to East Asia up to the Pacific Ocean. These mountainous regions are locations of high seismicity i.e. a history of earthquakes of magnitude greater than 3.5 on the Richter scale.

\section{Seismicity and Locating Regions of Infrasound Worldwide Along $34^{\circ}$ North Latitude}

The Third Correlation: Natural disasters like earthquakes, floods, volcano eruptions, landslides, drought, tsunami etc are visible, audible and very tangible 
to human senses. Some like solar flares, gamma-ray bursts are subtle and beyond the range of human senses but detected by scientific instruments. In the recent past, chronic psychological and physiological hazards appear to coexist with such physical hazards in these highly population dense regions of high seismicity along the 34th Parallel. Could this be due to some other environmental phenomenon which is also beyond the range of human senses? Pail Golden brings out that 'through an iterative process of combining Rayleigh wave travel times with infrasound travel times and a known azimuth, it can be shown that one single earthquake can cause multiple infrasound sources in a region' [5].

Studies have been carried out by the National Oceanographic and Atmospheric Administration (NOAA) in the USA in 1975 [6] The NOAA Report concludes that most abundant regions of infrasound identified originated in or near certain mountainous regions and appears likely to be associated with some kind of high speed wind flow interaction with the mountain. The global maps provided in this Report indicate that infrasound hotspots exist mostly in mountainous regions in North West of North America and South West of South America. Locations only in South Asia along the Himalayas (along $34^{\circ} \mathrm{N}$ latitude), in Tibet, Southern China and Mongolia are shown in Figure 4 extracted from the 1975 NOAA Report. The triangles show locations of intersections of infrasound waves from two different sources near the location. In West Asia the NOAA Report brought out that continuous infrasound waves were arriving in Tel Avi, Israel without bringing out maps of the infrasound source locations in this region.

Infrasound from Mountain Air Turbulence: The precise location of the "epicentre" of infrasound emissions is now to be determined by local studies alone. It is postulated that while earthquakes cause infrasound emissions before, during and after earthquakes, in some mountainous regions infrasound is

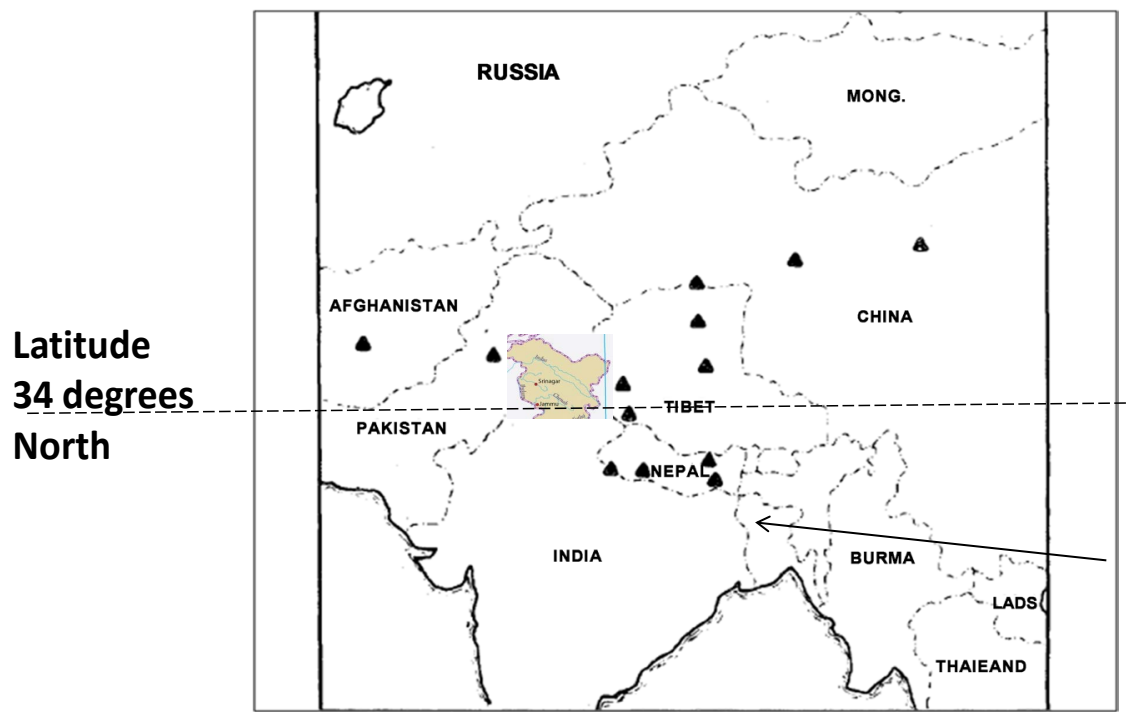

Figure 4. Intersections of infrasound from possible mountain-associated waves in the tibetan Area (with permission). Source: national oceanic \& atmospheric administration March 1975, Report No. NOAA ERL 317-WPL 37. 
sustained by mountain air turbulence most likely in U-shaped valleys that behave like acoustic cavities. Such sustained sources have been located in the Rocky Mountains, at Boulder in Colorado, USA. Here air accident rates rose by $40 \%$ over national average, where mid-day infrasonic signals were recorded every half an hour [7] established as due to mountain clear air turbulence. Similar detailed infrasound "epicentre" location studies are now needed in other such seismic and mountainous regions in Asia where infrasound emissions are also sourced by clashing tectonic plates like in the Himalayan mountain regions. The focus here is on the State of Jammu and Kashmir that may be intensely affected by all three triggering causes namely due to clashing tectonic plates, earthquakes and mountainous air turbulence.

More recently 2015 [8] D.N. Green deployed distributed arrays of infrasound sensors to record low-frequency sound waves in Central Asia, the Middle East, Southern Sudan and Northern Australia. His results are shown in Figure 5. The 35 source-to-array pairs for the array detections used within this study. Infrasound arrays are indicated in Figure 5 by the red triangles, sources by yellow stars and source-to-receiver great-circle paths by the red lines. This study shows that seismically affected mountainous regions along 34 degrees North latitudes and in other regions as well are significant regions of natural infrasound.

The US State of California has an extraordinary wide network of infrasound monitoring stations in its earthquake prone regions. The acoustic signals have significant amplitudes over large distances and are typically recorded at stations in 2006 up to $400 \mathrm{~km}$ from the source [9]. In $\underline{2007}$, the National Nuclear Center of the Republic of Kazakhstan, Kurchatov in Almaty has located daytime infrasound in this Central Asian State [10]. Infrasonic sources have been monitored across Europe using regional infrasound records for 2000-2007 [11] and in South Korea [12]. Approximately 60 infrasound stations are installed in the International Monitoring System (IMS) infrasonic network [Brown et al., 2002a]. When detected on several widely spaced infrasound arrays, the approximate location of observed events can be estimated. Infrasound arrays are currently being installed around the globe to assist in the enforcement of the Comprehensive Test Ban Treaty. The global scale at which these results are reported are not thus far substantiated by precise local surveys and studies to pin point the source of local infrasound in the MENA Region, and in West/South Asia regions along the killing fields of Latitude $34^{\circ} \mathrm{N}$.

\section{Regions of Natural Infrasound with Health Hazards \& Social Violence in Populations along $34^{\circ}$ North Latitude}

Fourth Correlation: Environmental Infrasound-The Silent Killer: Infrasound is very low frequency acoustic wave with frequencies ranging from 0.01 to $20 \mathrm{~Hz}$. For many decades infrasound was believed to be inaudible. However recent (2015) research indicates that contrary to belief that infrasonic noise and some low-frequency noise are inaudible it has been established that hearing does 


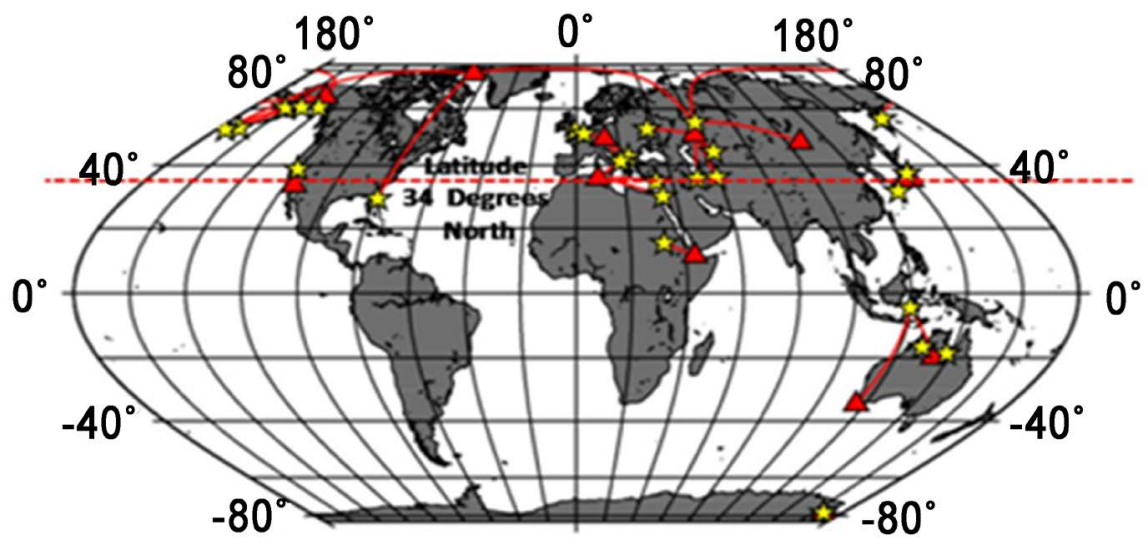

Figure 5. Some Infrasound source locations in West Asia, North America and Africa (2015). From: The spatial coherence structure of infrasonic waves: analysis of data from International Monitoring System arrays Geophys J Int. 2015; 201(1):377-389.

https://doi.org/10.1093/gji/ggu495 Geophys J Int|๔ Crown Copyright. Published by Oxford University Press on behalf of The Royal Astronomical Society 2015. You are not required to obtain permission to reuse figures (including tables) for academic, educational or non-commercial research for the following material provided full acknowledgment is given to the original source including Figure Number, Title of the Article, Author, Journal Title and Volume or Issue.

(https://academic.oup.com/gji/pages/rights_and_new_business_development).

not stop at $20 \mathrm{~Hz}$, as humans can hear infrasound up to $1 \mathrm{~Hz}$. Low frequency, long wave length sound is generated by natural sources such as:

- Earthquakes $(1 \mathrm{~Hz}$ to $12 \mathrm{~Hz})$;

- Clear Air Turbulence (1 Hz to $16 \mathrm{~Hz})$;

- Rock Fractures (2.0 to $8.0 \mathrm{~Hz}$ for different kinds of rocks);

- Volcanoes (in the $0.3-10 \mathrm{~Hz}$ frequency range);

- Cyclones (>10 Hz; up to $135 \mathrm{db}$ at $100 \mathrm{~km} / \mathrm{h}$ );

- Thunder;

- Atmospheric disturbances;

- Meteors.

Health Hazards of infrasound at different frequencies and amplitudes are presented in Figure 6. Infrasound is also generated by man-made sources: trucks, cars, air and rail traffic, heavy machinery etc. Wind turbulence in mountainous regions generates infrasound where it can cause an adverse effect on aviation.

Windmills are also a source of infrasound due to turbulent air flow past its blades and its rotating machinery, where it was found to be an annoyance to technicians working in close proximity to a large-scale wind farm [13]. This is emerging as tangible hazards that could affect a large part of renewable energy generation systems worldwide. Intense research is currently underway in this area to understand and mitigate windmill low frequency noise. Exposure of humans to infrasound at specific frequencies, amplitudes and durations are responsible for harmful effects like sustained annoyance and irritation [14] and aversion to live in the locality [15]. Sleep disorders [16] were noted when exposed to infrasound at frequencies between 6 and $16 \mathrm{~Hz}$ at $10 \mathrm{db}$. 


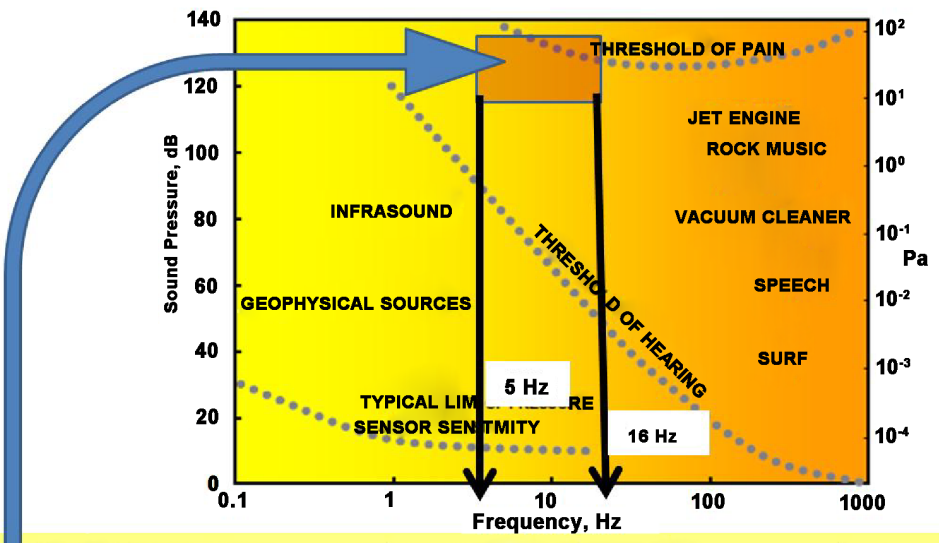

MENTAL AILMENTS: Depression, apthy, loss of concentration. PHYSIOLOGICAL AILMENTS: Hearing Disabilities-Damages the Ears SIEEP DISORDERS, feeling of fatigue, drowsiness, nausea. OTHERS: Central nervous system, cardiovascular and respiratory systems

Figure 6. Health hazards of infrasound. Source of Basic Chart Only: Bedard J and Georges TM “Atmospheric infrasound" Figure 3, "Threshold of basic hearing” with permission of the author.

The effects of long-term exposure to infrasound were studied in 40 active Swiss Air Force pilots who were exposed to infrasound of 14 or $16 \mathrm{~Hz}$ at $125 \mathrm{db}$. Somatic and psychic functions were affected in the following ways: decrease in systolic blood pressure, increase in heart rate and blood pressure, impaired alertness and altered hearing threshold and time perception [17]. The findings of Gavreau [18] in the infrasonic range between 1 and $10 \mathrm{~Hz}$ are truly unnerving. They include lethal infrasonic pitch lies in the $7 \mathrm{~Hz}$ range; small amplitude increases affect human behavior in this pitch range; intellectual activity is first inhibited, blocked, and then destroyed; as the amplitude is increased, several disconcerting responses have been noted.

These responses begin as neurological interferences; the action of the medulla is physiologically blocked, its autonomic functions cease. It is also to be noted that in World War II, Nazi engineers used infrasound to stir up hostilities of crowds gathered. A news article from a very reputed news source (Reuters) brings out a single experiment in 2003 involving 750 people exposed randomly to brief infrasound episodes in between normal musical sounds from an orchestra that could mask other pleasant musical sounds. It is recorded that $22 \%$ of the population reported discomfort and uneasiness during whenever the random exposures to infrasound emissions too place. The details of the experiment are copyrighted [19].

Hearing Disabilities: A Marker for Infrasound Hazards: Hearing disability in human species has a multiplicity of genetic and medical causes. This physiological health factor is one among many hazards of exposure to infrasound. Disabling hearing loss refers to hearing loss greater than $40 \mathrm{~dB}$ in the better hearing ear in adults (15 years or older) and greater than $30 \mathrm{~dB}$ in the better hearing ear in children ( 0 to 14 years). Hearing loss is unequally distributed over 
the world. Even though the MENA (Middle East \& North Africa) region lies around the $34^{\text {th }}$ parallel where health effects of infrasound are most expected, yet the WHO study [20] shows it to be a region with least hearing disabilities in the world (4\%). On the other hand South Asia, East Asia and Asia Pacific combined have the highest (59\%) i.e. over half the deaf and partially deaf people live in these regions.

Hearing Disabilities in the State of Jammu \& Kashmir: (northern India) around the $34^{\circ}$ North latitude appears to be a direct function of frequency of earthquakes in the region. The slow-motion of tectonic plate collision has created one of the most active "earthquake hotspots". However, no local attempts so far have been made to correlate these earthquake "hotspots" with "infrasound hotspots". A time-series analysis shows strong correlation exists between the frequency of earthquakes between 1981 and 2011 and increase of hearing disabilities as shown in the Figure 7 [21]. This is also brought out in Table 1 that percentage of population with hearing disabilities is almost directly proportional to frequency of Earthquakes.

Hearing Disabilities along $34^{\circ}$ North Latitude No data was available for East Asia and Asia Pacific regions (China and Japan) around this latitude. The

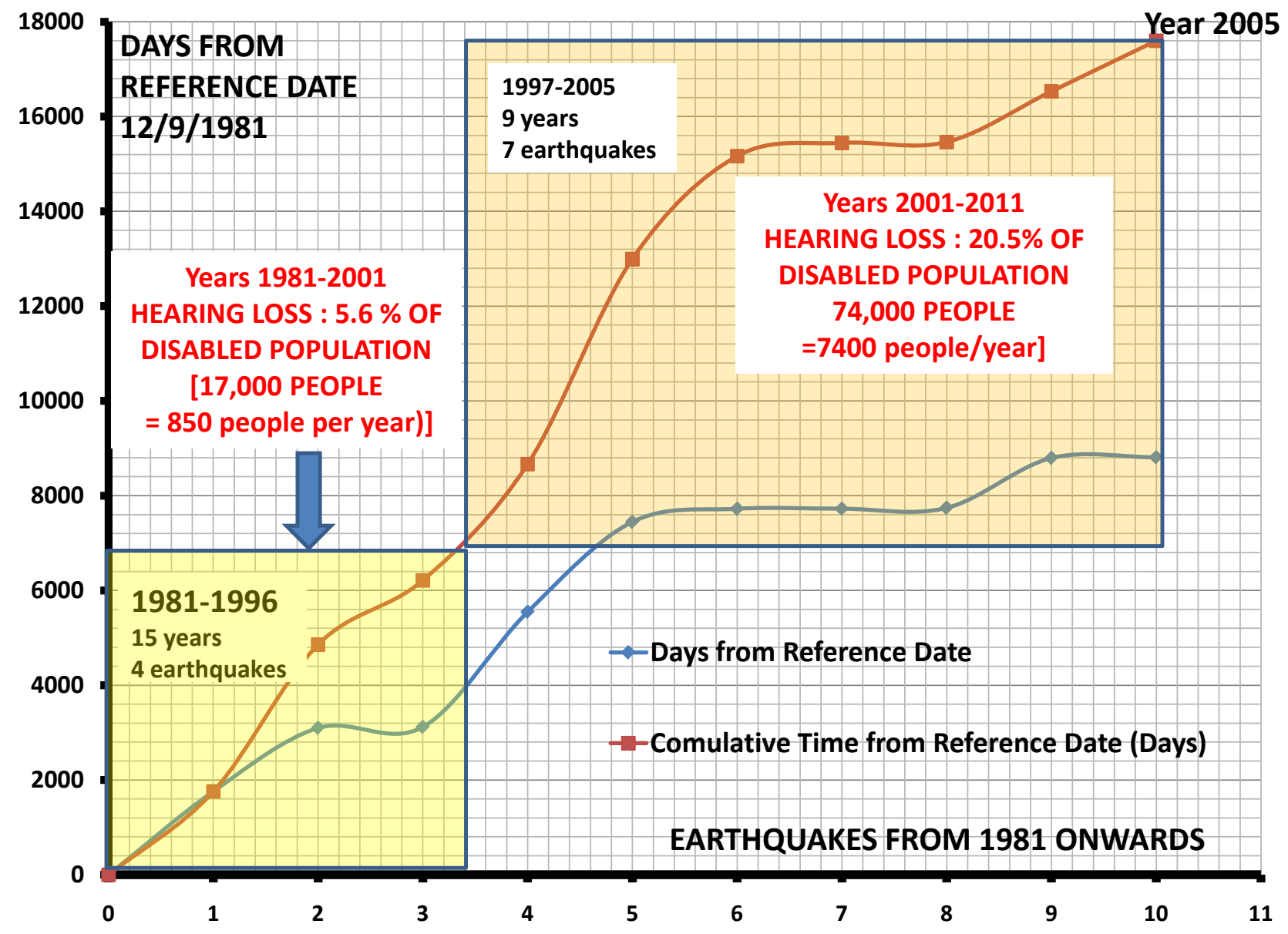

Figure 7. Recent earthquakes linked to hearing disabilities in Kashmir region. 
Table 1. Hearing disabilities as a function of earthquake frequency in the state of Jammu and Kashmir.

\begin{tabular}{rccccc}
\hline Period & & $\begin{array}{c}\text { No of } \\
\text { earthquakes }\end{array}$ & $\begin{array}{c}\text { Earthquake } \\
\text { Frequency } \\
\text { (Years between earthquakes) }\end{array}$ & $\begin{array}{c}\text { Earthquakes per } \\
\text { year }\end{array}$ & $\begin{array}{c}\text { Hearing } \\
\text { disabilities } \\
\text { (\% population) }\end{array}$ \\
\hline a) $1981-1996$ & 15 years & 4 & 3.75 & 0.27 & 5.6 \\
b) $1997-2005$ & 9 years & 8 & 1.1 & 0.89 & 20.5 \\
& & Ratio (B/A) & & 3.3 & 3.7 \\
\hline
\end{tabular}

Note: All India average for hearing disabilities in 2001 was $5.8 \%$. Global average was $10 \%$.

MENA region having the least hearing disabilities; and no detailed data for specific locations was available. Hence the data analysed pertains Northern regions of South Asia and the USA.

Hearing Disabilities in USA around $34^{\text {th }}$ Parallel In the USA the States of Montana, Wyoming, Idaho and New Mexico that are located in high seismic zones due to colliding Pacific and American tectonic plates in the Rocky Mountain region near $34^{\text {th }}$ Parallel are known locations for environmental infrasound. Here also is the maximum percentage $(3 \%)$ of State population with hearing disabilities is $30 \%$ higher compared to US National average of $2.3 \%$ with hearing disabilities [22]. It needs to be noted that advanced public health infrastructure is well established all over the USA, unlike in the highly populated developing regions in Asia.

Seismicity, Natural Infrasound, Psychological Ailments and Terrorism: Latitude 34 degrees north is also observed to be a focal geographic parameter that correlates regions of high seismicity (earthquakes), environmental infrasound emissions. Some regions in South Asia having advanced medical research capabilities have reported unusually high levels (52\% - 62\% of the population) [23] of psychological ailments ranging from sustained annoyance and irritation to sustained social unrest and disorder, and many forms of mental illness strikingly analogous to the effects of exposure to infrasound at frequencies $5 \mathrm{~Hz}$ to $26 \mathrm{~Hz}$ and sound pressure levels ranging from 120 to $135 \mathrm{~dB}$ ] as shown in Figure 6.

Other regions report unprecedented and fierce ethnic conflict tendencies all leading on to barbaric acts of terrorism have almost become a way of daily life. These regions are currently the homes of global terrorism where ceaseless ethnic conflict has fanned out fiercely into the rest of the world, to their north, south, east and west as shown in Figure 8; while devastating peaceful life in their own regions as may be seen in Figure 9 which illustrates how the highest numbers of suicide attacks are within the regions located on $34^{\circ}$ North latitude.

Again in Northern India where systematic published public records are available online over the last 30 years, time-series analysis shows strong correlation between casualties due to terrorism and frequency of earthquakes in the Kashmir Region, As intensity of earthquakes increase, casualties due to social disorder and violence also increase, and vice-versa (Figure 10). 


\section{a) Transnational attacks:}

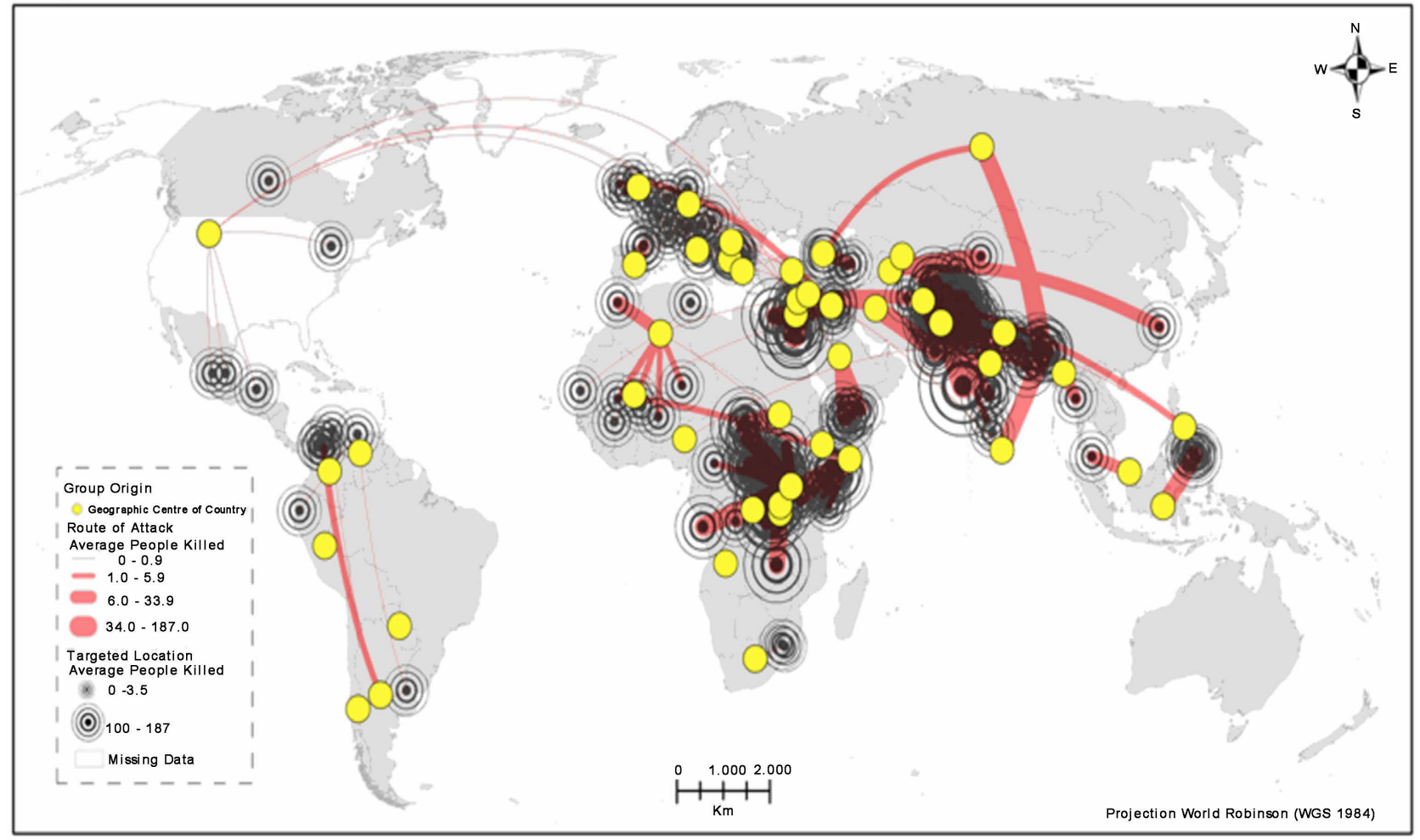

Figure 8. The Geography of Terrorism. Global patterns of attack, 2001-2011. (with permission). Susan L. Cutter April 11, 2003 https://www.directionsmag.com/article/3751.

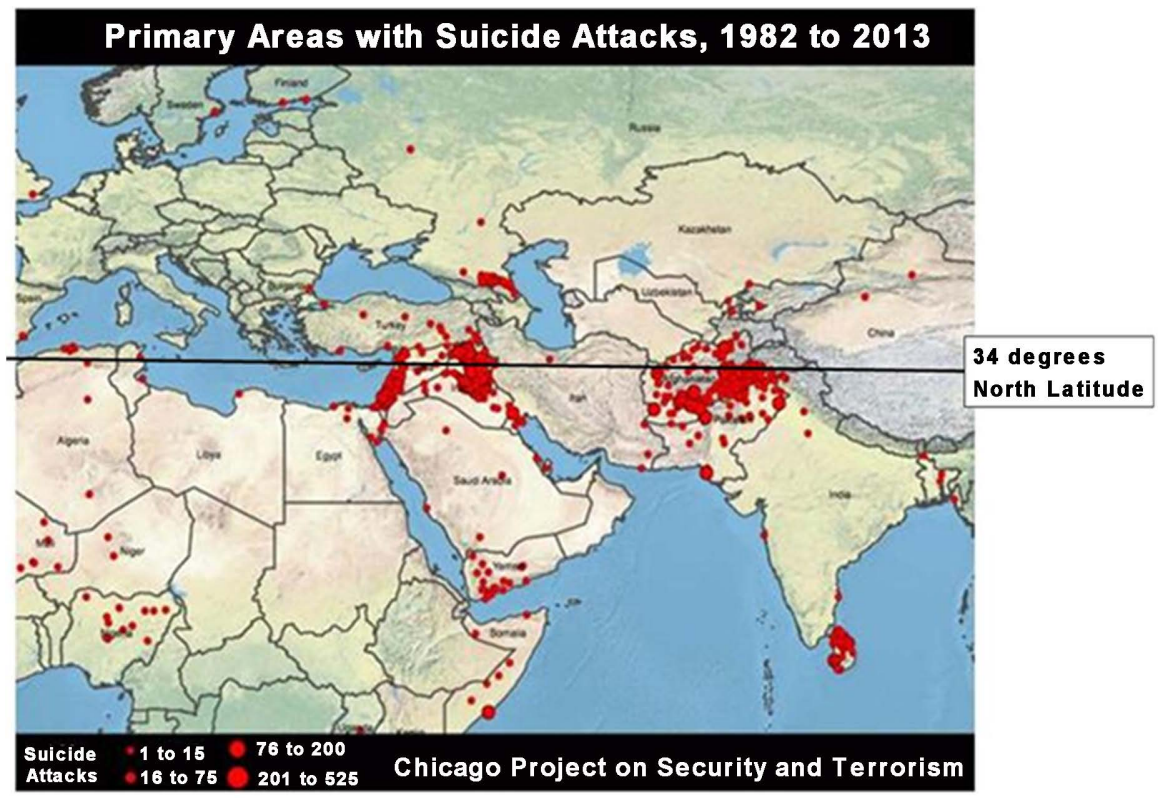

Figure 9. Geography of terrorism-suicide attacks. (with permission) Global4 Cast, https://global4cast.org/2017/06/17/suicide-attacks-when-where-how-many/.

Focusing more precisely (within \pm 1 degree latitude) on Latitude $34^{\circ}$ North on known locations with a preponderance of social disorder and violence one sees 


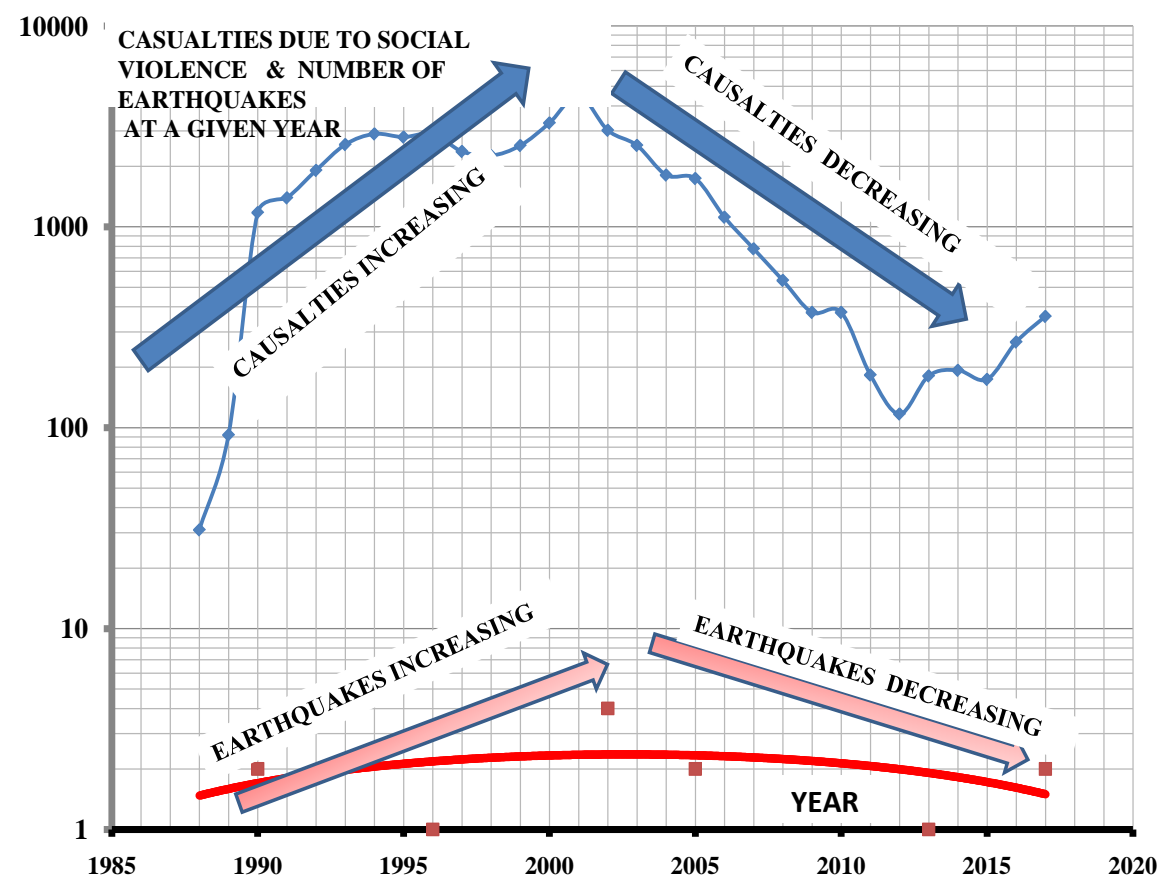

Figure 10. Relationship between earthquakes and social violence.

they are all afflicted by this fierce ethnic conflict all lie along $34^{\circ}$ North latitude. These are shown in Table 2 that gives an insight into the likely existence of yet another subtle (invisible and inaudible) environmental hazard: infrasound.

As the poet Mumtaz brings out for one such region on the $34^{\text {th }}$ parallel, the Valley of Kashmir in India, "The valley of tulip fields! How sorrowful has this valley become! Someone is choking its life out". Science now can now find an answer to man-planet problems that poetry alone could have identified.

\section{Verification of the Extent of Correlation between Earthquakes, Social Disorder, and Infrasound at Specific Locations along $34^{\circ}$ North Parallel}

Each of 55 locations along $34^{\circ}$ North Parallel [24] has been studied in detail to ascertain the presence of earthquakes, social disorder, and infrasound hotspots as analysed through the correlations. By social disorder is meant terrorism, civil war, intractable border disputes, island disputes, ocean fishing rights disputes, race riots, and large scale sectarian violence, ethnic violence, violence against women, domestic violence, violent youth, gangsters and violent crime, etc. The findings are shown in Table 3. The continents, regions and locations benchmarked for this Study by the $34^{\text {th }}$. Parallel are:

1) In North Africa: Morocco, Algeria Tunisia.

2) In Asia: Iraq, Lebanon, Syria, Jordan, Israel, Iran, Afghanistan (Kabul, Tora Bora Caves), Northern India (Kashmir Valley) and Pakistan (Rawalpindi, Peshawar); China(Tibet, Qinghai, Sichuan, Gansu, Shaanxi, Henan, Anhui, Jiangsu, East China Sea) and Japan (Island of Honshu, Yamaguchi Prefecture, Tokushima Prefecture, Wakayama Prefecture, Nara Prefecture). 
Table 2. Distribution of locations/regions of high seismicity (Earthquakes $>$ Richter scale $>5.5$ ) Congruent with high ethnic conflict (around latitude $34^{\circ} \mathrm{N}$ ).

\begin{tabular}{|c|c|c|c|c|}
\hline Sl. No & Location/Region & Latitude (Degrees) & $\begin{array}{l}\text { Deviation from Average } \\
\text { Latitude (Degrees) }\end{array}$ & Societal Characteristic of the Region/Location \\
\hline 1 & Kabul, Afghanistan & 34.56 & 0.88 & $\begin{array}{l}\text { Kabul is a city that for centuries has been at the cross-roads } \\
\text { of war and social turmoil. It is periodically the scene of } \\
\text { deadly suicide bombings ( } 38 \text { in the last } 10 \text { years). The Afghan } \\
\text { government called the actions of the terrorist's war crimes. }\end{array}$ \\
\hline 2 & $\begin{array}{l}\text { Tora Bora Caves } \\
\text { Afghanistan }\end{array}$ & 34.12 & 0.44 & $\begin{array}{l}\text { Tora Bora was known to be a stronghold location of the } \\
\text { Taliban, used by military forces against the Soviet Union } \\
\text { during the } 1980 \text { s. Recently bombed by the world's largest } \\
\text { conventional bomb. }\end{array}$ \\
\hline 3 & Srinagar, India & 34.08 & 0.41 & $\begin{array}{l}\text { Srinagar is the focus of social disorder and hotbed of } \\
\text { cross-border terrorist activity with frequent bursts of social } \\
\text { turmoil and violence. }\end{array}$ \\
\hline 4 & Lebanon & 33.85 & 0.18 & $\begin{array}{l}\text { Region of increasing sectarian tensions and sustained } \\
\text { full-scale civil war. }\end{array}$ \\
\hline 5 & $\begin{array}{l}\text { Peshawar } \\
\text { Pakistan }\end{array}$ & 34.00 & 0.00 & $\begin{array}{l}\text { This region has historically been the gateway for historical } \\
\text { migrations and violent invasions from West and Central Asia } \\
\text { into South Asia. }\end{array}$ \\
\hline 6 & Damascus & 33.51 & -0.16 & $\begin{array}{l}\text { Historically a region characterised by armed sectarian } \\
\text { violence for centuries. }\end{array}$ \\
\hline 8 & Baghdad & 33.31 & -0.36 & $\begin{array}{l}\text { Known as The City of Blood and sectarian violence for } \\
\text { centuries. }\end{array}$ \\
\hline
\end{tabular}

Table 3. Strength of correlations between earthquakes, infrasound and health hazards in 55 locations on latitude $34^{\circ} \mathrm{N}$.

\begin{tabular}{|c|c|c|c|c|c|}
\hline Sl. No & Continent & Region/Country & $\begin{array}{l}\text { Strong } \\
\text { Correlation }\end{array}$ & $\begin{array}{c}\text { Weak } \\
\text { Correlation }\end{array}$ & Total \\
\hline 1 & $\begin{array}{l}\text { North } \\
\text { Africa }\end{array}$ & Morocco, Algeria Tunisia & 3 & - & 3 \\
\hline 2 & West Asia & Iraq, Lebanon,Syria, Jordan, Israel, Iran & 4 & - & 4 \\
\hline 3 & $\begin{array}{l}\text { South } \\
\text { Asia }\end{array}$ & Afghanistan, Northern India and Pakistan & 5 & - & 5 \\
\hline 4 & China & Tibet, Qinghai, Sichuan, Gansu, Shaanxi, Henan, Anhui, Jiangsu, East China Sea & 9 & - & 9 \\
\hline 5 & $\begin{array}{l}\text { South } \\
\text { Korea }\end{array}$ & Hamilton Islands \& South Korean Straits & 2 & 2 & 2 \\
\hline 6 & Japan & $\begin{array}{l}\text { Island of Honshu, Yamaguchi Prefecture, Tokushima Prefecture, Wakayama } \\
\text { Prefecture, Nara Prefecture }\end{array}$ & 3 & 2 & 5 \\
\hline 7 & USA & $\begin{array}{l}\text { Miyakejima and Mikurajima, Hector California, Northridge California, Lucerne } \\
\text { California, Bear Mountain California, Pasadena California, Claremont California, } \\
\text { Malibu California, Banning California, Pasadena California Wittier California, } \\
\text { Hector California, San Miguel Island California, California-Santa Rosa Island, } \\
\text { Anacapa Island California, Los Angeles California, Arizona, New Mexico, Texas } \\
\text { Oklahoma-Durant and Hugo, Arkansas, Mississippi, Alabama, } \\
\text { Georgia-Athens, South Carolina_Columbia North Carolina. }\end{array}$ & 2 & 23 & 25 \\
\hline \multirow{2}{*}{ Total } & & WITH USA & $28(51 \%)$ & $27(49 \%)$ & 55 \\
\hline & & WITHOUT USA (Asia \& North Africa) & $26(87 \%)$ & $4(13 \%)$ & 30 \\
\hline
\end{tabular}

3) In USA: California, Arkansas, Mississippi, Alabama, Georgia-Athens, South Carolina-Columbia, North Carolina.

It is seen from this Table that $87 \%$ of these specific locations on Latitude 34 
degrees north latitude had all three driving forces ongoing, indicating a strong correlation between earthquakes, social disorder, and infrasound in regions on planet earth near Latitude $34^{\circ}$ North. A new natural hazard inimical to life on planet earth has been identified. The next step forward needed therefore is to carry out specific field studies and where the infrasound hotspot is located; and then provide technological solutions to neutralize infrasound emissions where required.

\section{Solutions: New Technologies for Alleviating the Harmful Effects of Environmental Infrasound}

The global locations of infrasound obtained from published papers are indicated by a small mark on a World Map. This is useful to locate a general location but not the precise location of the infrasound hot spot. This is obtainable only by an experimental study by actual field measurements to precisely locate and monitor infrasound hotspot activity in the region. Once the precise location and characteristics of the infrasound hotspot is known, measures to neutralize these harmful environmental emissions can be initiated. It is reported that Passive Noise Cancellation Technologies can be as simple as providing acoustic fences around the infrasound hotspot once located Active noise control (ANC), also known as noise cancellation, or active noise reduction (ANR), is a method for reducing unwanted sound by the addition of a second sound specifically designed to cancel the first.

The process is like smoothing the waves on the surface of a lake by creating anti-waves so that the peaks and the valleys of the two sets of waves cancel each other. This is not sound masking that adds a different kind of noise to cover-up the undesired noise. High frequency waves are difficult to reduce in three dimensions due to their relatively short audio wavelength in air. The most effective noise reduction in three-dimensional space involves low frequency sounds and Active Noise Cancelation is best suited for low frequencies [25]. Adewumi et al. bring out that "Modern active noise control is generally achieved through the use of analog circuits or digital signal processing. Adaptive algorithms are designed to analyze the waveform of the background aural or non-aural noise, then based on the specific algorithm, generates a signal that will either phase shift or invert the polarity of the original signal. This inverted signal is then amplified and a transducer creates a sound wave directly proportional to the amplitude of the original waveform, creating destructive interference. This effectively reduces the volume of the perceivable noise" [26].

More research and innovations are needed diminish infrasound due to mountain air turbulence as an extension of ongoing research to reduce air turbulence from trailing edges of windmill blades. Once the precise location and causes of these "hot spot" emissions are precisely identified, design and development of such devices will be site specific. This work will consolidate the expansion of knowledge in the field of electroacoustics for the benefit of all man- 
kind by adding a new dimension to interpretation and alleviation of global terrorism by alleviating the harmful effects of environmental infrasound pollution. The serene sounds of silence would once again descend on mankind in these disturbed areas at the boundaries of colliding tectonic plates and seismic "hot spots" in all continents and all affected nations. Better understanding of geo-acoustics of environmental infrasound pollution could well usher joy instead of sorrow in affected regions and be the precursor to a new era of world peace.

\section{Summary of Findings}

Findings of this statistical study are summarized below:

1) Infrasound is an inaudible sound that is a deadly physiological and psychological hazard to all mankind.

2) Latitude $34^{\circ}$ North is a geological "killing field" on planet earth. Millions have been killed due to earthquakes in the regions around this latitude. In the 20th century alone, over two million people have died due to earthquakes on the latitude $34^{\circ}$ North.

3) Latitude $34^{\circ}$ North lies precisely along the boundaries of colliding tectonic plates. It harbours the most seismic (earthquake prone) regions and mountainous regions of the planet.

4) Seismicity-earthquakes, rock fractures, and colliding tectonic plates, and mountain clear air turbulence-all release natural energies that are manifested as environmental infrasound.

5) $87 \%$ of fifty five specific locations, on $34^{\circ}$ North latitude, are earthquake prone and infrasound regions and exhibit social violence.

6) The principal markers of people afflicted by exposure to infrasound are:

a) Physiological: Hearing Disabilities.

b) Sustained state of annoyance and anger for no apparent reason.

7) In South Asia, in one region that is highly seismic and is a mountainous valley:

a) Hearing disabilities are 10 times the national average and twice the world average.

b) The intensity of occurrence of hearing disabilities is in direct proportion to frequency of earthquakes.

c) Casualties due to extreme social violence increase and decrease as frequency of earthquakes increase and decrease.

d) Almost all the known manifestations of health hazards due to exposure to infrasound at 5 to $16 \mathrm{~Hz}$ frequency and $120-140 \mathrm{~dB}$ amplitude have been recorded in a large percentage of the total population.

8) All published maps of infrasound hotspots from 1975 to 2015 indicate the locations approximately. Precise studies location-wise are yet to be published.

9) Precise location of infrasound sources using ground-based sensors and existing infrasound monitoring stations owned and operated by CTBTO especially 


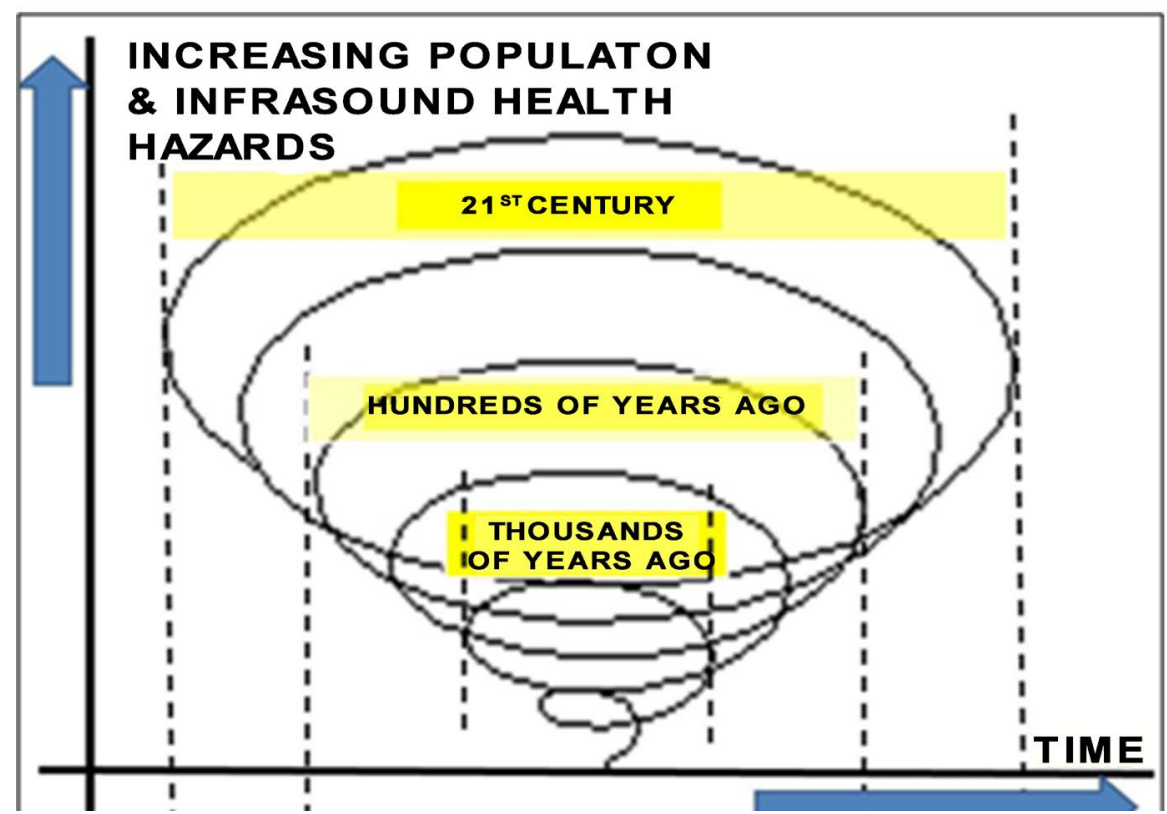

Figure 11. Infrasound: A spiraling natural hazard.

along latitude $34^{\circ}$ North need to be carried out urgently focusing in regions and locations with abnormal hearing disabilities and extreme social violence.

10) In the longer term, satellite based sensors may be deployed that have the capability to locate infrasound hotspots precisely.

11) Infrasound cancellation technologies can be developed to make these habitats free of acute health hazards of environmental infrasound.

12) Modern science and technology may thus be deployed to resolve horrific problems of social disorder and violence in geographical regions around $34^{\circ}$ North latitude that have existed for centuries and now threaten whole civilizations.

\section{Conclusions}

It has been concussively established through four correlations that latitude $34^{\circ} \mathrm{N}$ which has for centuries been the seismic killing field of planet earth is now emerging sociologically as the most dangerous regions due to environmental infrasound that threaten civilization as a whole, as populations explode and seismicity increases. A new natural hazard has emerged in this region. In some regions in South Asia where extensive health surveys have been carried out, it is seen that hearing disabilities and social disorder/violence escalate with increasing frequency of earthquakes and vice versa. Hearing disabilities and mental illnesses are rapidly escalating as earthquakes continue inexorably in these regions in Asia as also in Western USA. Infrasound is now seen to be a dangerous natural hazard that is expanding in these regions by spiraling outwards as regional populations explode as shown in Figure 11.

Urgent action is now needed by world governments and the international scientific community to step in, locate the infrasonic hotspots with precision, 
neutralize these hazardous low frequency sound emissions, set up chains of infrasound monitoring stations locally, and draw up regional Health Security Systems as a proactive response to arrest the insidious and now accelerating growth of this new environmental hazard-infrasound hotspots-before the region of killing fields on planet earth spreads out to infect and destroy human civilization worldwide.

\section{Acknowledgements}

Grateful thanks are due to Dr V. Siddhartha for sharing his valuable time and for his positive encouragement to write this paper. I am also extremely grateful to the Editorial Staff of the Journal of Earthquake Research for their patient and clear guidance that I needed to make this paper suitable for publication in their Journal.

\section{References}

[1] Philip England Earthquakes around Latitude 340 North. Oxford University, from philip.england@earth.ox.ac.uk Plate Tectonics. https://www.britannica.com/science/plate-tectonics

[2] Murphy, J.B. and van Andel, T.H. Plate Tectonics GEOLOGY. https://www.britannica.com/science/plate-tectonics

[3] Wikipedia: Seismicity. https://en.wikipedia.org/wiki/Seismicityoriginal

[4] Bolt, B.A. (2018) Earthquake Geology. https://www.britannica.com/science/earthquake-geology

[5] Golden, P. (2008) Infrasound Case Studies. Southern Methodist University, Dallas. http://www.geology.smu.edu/ seismic/infrasound/casestudies6.pdf

[6] Greene, G.E. and Howard, J. (1975) Natural Infrasound: A One Year Global Study. National Oceanic \& Atmospheric Administration, Report No. ERL 317-WPL 37.

[7] Bedard, A.J. (1998) NOAA Project MCAT, Experimental Technology Lab.

[8] Green, D.N. (2015) The Spatial Coherence Structure of Infrasonic Waves: Analysis of Data from International Monitoring System Arrays. Geophysical Journal International, 201, 377-389. https://doi.org/10.1093/gji/ggu495

[9] Cochran, E.S. and Shearer, P.M. (2006) Infrasound Events Detected with the Southern California Seismic Network. Geophysical Research Letters, 33, L19803. https://doi.org/10.1029/2006GL026951

[10] Mikhailova, N.N. and Sokolova, I.N. (2007) Kazakhstan National Monitoring System of Nuclear Explosions and Earthquakes.

https://www.slideserve.com/deiter/kazakhstan-national-monitoring-system-of-nucl ear-explosions-and-earthquakes http://www.fdsn.org/media/meetings/2007/KZNet_2007.ppt

[11] Le Pichon, A., Vergoz, J., Herry, P. and Ceranna, L. (2008) Analyzing the Detection Capability of Infrasound Arrays in Central Europe. Journal of Geophysical Research, 113, D12115. https://doi.org/10.1029/2007JD009509

[12] Stump, B.W., McKenna, S.M., Hayward, C. and Kim, T.-S. (2002) Seismic and Infrasound Data and Models at Near-Regional Distances. Southern Methodist University, Dallas.

[13] Inagaki, T., Li, Y. and Nishi, Y. (2015) Analysis of Aerodynamic Sound Noise Gen- 
erated by a Large-Scaled Wind Turbine and Its Physiological Evaluation 27 March 2014. International Journal of Environmental Science and Technology, 12, 1933-1944. https://doi.org/10.1007/s13762-014-0581-4

[14] Lindström, I.M., et al. (1997) The Effects of Ultrasound on Humans. Rep., Umea University, Umeå, 33, 1-42.

[15] Persinger, M.A. (2014) Infrasound, Human Health, and Adaptation: An Integrative Overview of Recondite Hazards in a Complex Environment. Natural Hazards, 70, 501-525. https://doi.org/10.1007/s11069-013-0827-3

[16] Landstrom, U. and Bystrom, M. (1984) Infrasonic Threshold Levels of Physiological Effects. Journal of Low Frequency Noise, Vibration and Active Control, 3, 167-173. https://doi.org/10.1177/026309238400300402

[17] Lindström, I.M., et al. (1997) The Effects of Ultrasound on Humans. Rep., Umea University, Umeå, 33, 1-42.

[18] Vassilatos, G. (1999) “Lost Science” Limited Permission Granted to Use This Material in Other Presentations from "Deadly Sounds" Dr. Vladimir Gavreau.

[19] Reuters: The Associated Press. http://www.nbcnews.com/id/3077192/ns/technology_and_science-science/t/infraso und-linked-spooky-

[20] WHO (2012) Global Estimates on Prevalence of Hearing Loss Mortality and Burden of Diseases and Prevention of Blindness and Deafness.

[21] Naik, A.A. and Selvarajan, E. (2015) Disabled Population: A Temporal Study of Jammu and Kashmir. Journal of Business Management \& Social Sciences Research, 4, 611-617.

[22] Hearing Disabilities in USA. http://libguides.gallaudet.edu/content.php?pid=119476\&sid=1029190

[23] Muntazar (2016) Kashmir Mental Health Report 2015. Médecins Sans Frontières (MSF), The University of Kashmir, Institute of Mental Health and Neurosciences (IMHANS).

[24] 34th Parallel North. https://en.wikipedia.org/wiki/34th_parallel_north

[25] Infrasound "Wikipedia". https://www.google.co.in/search?source=hp\&q=active+noise+cancellation\&oq=acti $\underline{\mathrm{ve}+\text { noise\&gs }}$

[26] Adewumi, et al. (2015) Reducing Infrasound and Low Frequency Noise from Wind Turbine Blades and Rotors using Active Noise Cancellation. Renewable Bioresources, 3, 1-11. http://www.hoajonline.com/journals/pdf/2052-6237-3-3.pdf 